\title{
COLONY SEX RATIOS VARY WITH BREEDING SYSTEM BUT NOT RELATEDNESS ASYMMETRY IN THE FACULTATIVELY POLYGYNOUS ANT PHEIDOLE PALLIDULA
}

\author{
Denis Fournier, ${ }^{1,2}$ Laurent Keller, ${ }^{3}$ Luc Passera, ${ }^{4}$ and Serge Aron ${ }^{1}$ \\ ${ }^{1}$ Department of Animal Biology, Behavioral and Evolutionary Ecology, Université Libre de Bruxelles, Avenue F.D. Roosevelt, 50, \\ B-1050 Brussels, Belgium \\ ${ }^{2}$ E-mail: Denis.Fournier@ulb.ac.be \\ ${ }^{3}$ Institute of Ecology, University of Lausanne, Bâtiment de Biologie, CH-1015 Lausanne, Switzerland \\ ${ }^{4}$ Laboratory of Ethology and Animal Cognition, University Paul-Sabatier, 118, route de Narbonne, F-31062 Toulouse, France
}

\begin{abstract}
We investigated sex allocation in a Mediterranean population of the facultatively polygynous (multiple queen per colony) ant Pheidole pallidula. This species shows a strong split sex ratio, with most colonies producing almost exclusively a single-sex brood. Our genetic (microsatellite) analyses reveal that $P$. pallidula has an unusual breeding system, with colonies being headed by a single or a few unrelated queens. As expected in such a breeding system, our results show no variation in relatedness asymmetry between monogynous (single queen per colony) and polygynous colonies. Nevertheless, sex allocation was tightly associated with the breeding structure, with monogynous colonies producing a male-biased brood and polygynous colonies almost only females. In addition, sex allocation was closely correlated with colony total sexual productivity. Overall, our data show that when colonies become more productive (and presumably larger) they shift from monogyny to polygyny and from male production to female production, a pattern that has never been reported in social insects.
\end{abstract}

Key words.-Ants, kin selection, polygyny, queen-worker conflict, split sex ratio.

Received October 28, 2002. Accepted January 6, 2003.

Breeding system - the number, relationships, and relative reproductive output of group members-constitutes a key feature of social life (Ross 2001). Over recent years, it has become clear that the organization of ant societies, especially the number and identity of reproductive queens, is extremely variable (reviewed in Bourke and Franks 1995; Keller 1995; Crozier and Pamilo 1996). Such variation is important because it affects the relatedness among colony members and thus the indirect benefits workers gain by helping to raise the brood. Variation in the breeding system also has become a topic of interest to molecular ecologists and evolutionary biologists because it is predicted to alter the allocation of resources between growth and reproduction (Pamilo 1991b; Herbers et al. 2001; Reuter and Keller 2001), the relative investment into male and female sexuals (Trivers and Hare 1976; Pamilo 1991b; Chapuisat and Keller 1999), and the interplay of conflict and cooperation in social evolution (Queller and Strassmann 1998; Keller and Chapuisat 1999; Keller and Reeve 1999).

The aim of this study was to characterize the breeding system of the ant Pheidole pallidula and to determine whether and to what extent variation across colonies correlate with patterns of allocation of resources between sexes. We selected this ant because of the two following characteristics. First, $P$. pallidula has a relatively simple breeding structure. Queens are strictly monandrous, mating occurs between unrelated individuals (Fournier et al. 2002), and workers are completely sterile (Passera 1978). The number of queens varies across colonies (Aron et al. 1999; Fournier et al. 2002), and it has been suggested that polygynous (multiple-queen) colonies may have anything from unrelated to full-sister queens (Aron et al. 1999). However, the genetic data that were available (data from two allozyme loci with low polymorphism) did not allow inference of the relatedness between queens. In the present study we used four highly polymorphic microsatellites (Fournier et al. 2002) to assess the number of queens per colony and to determine whether these queens are related. Second, an interesting feature of this species is that sex ratios are extremely split, with colonies specializing in the production of male or female sexuals (Keller et al. 1996; Aron et al. 1999; this study). Three leading hypotheses have been proposed to account for the common occurrence of split sex ratio in this and other ant species.

The first of these hypotheses holds that differences in sex allocation are due to differences in relatedness asymmetry (the relatedness ratio of workers to males and workers to new queens) across colonies. In Hymenoptera, females are diploid and males are haploid, and this difference typically results in asymmetries in genetic relatedness among colony members. Relatedness asymmetries cause colony members to have different inclusive fitness functions, leading to queen-worker conflict over relative allocation of resources in the two sexes (Trivers and Hare 1976; Charnov 1978; Nonacs 1986; Pamilo 1991a). Queens are expected to favor a 1:1 ratio of the sexes, but workers are expected to adjust the sex ratios depending on their relatedness to male versus female brood. When relatedness asymmetries within a colony exceed the population average workers should specialize on producing winged females (gynes), but when relatedness asymmetries fall below this average they should specialize on producing males (Boomsma and Grafen 1990; Ratnieks 1991; Boomsma 1993; Bourke and Chan 1994; Ratnieks and Boomsma 1997). Thus, if queen number varies between colonies of $P$. pallidula, and if nestmate queens are related, workers should favor raising mainly winged females in monogynous (single-queen) colonies and males in polygynous colonies because polygyny decreases relatedness asymmetry. When queens are unrelated, however, no variation in relatedness asymmetries occurs and the relatedness asymmetries hypothesis does not predict sex ratios to vary in function to the number of queens per colony (Boomsma 1993).

The second hypothesis asserts that resource level has a 
proximate effect on sex ratio, because it affects caste determination among the diploid brood. Food-constrained colonies (due to a limited worker force or temporal variations in quality and/or quantity of food) should produce workers rather than winged females, while their haploid brood will still develop into adult males, promoting a male-biased sex ratio. On the other hand, well-fed colonies should rear both males and winged females, with a relative overinvestment in winged females. Thus, small colonies are predicted to have more male-biased sex ratios than larger ones, because colonies produce the cheaper sex at times of scarcity and small colonies presumably experience more scarcity than larger ones (Nonacs 1986; Crozier and Pamilo 1992). The multifaceted parental investment hypothesis (Rosenheim et al. 1996) provides another explanation for the resource-abundance hypothesis by proposing that resource-limited colonies specialize on the production of males, which require less energy to produce than gynes, whereas colonies with sufficient resources but limited by the rate of brood production specialize on the production of the most costly sex, that is, gynes.

Finally, the queen replenishment hypothesis holds that the production of new queens occurs preferentially or only in colonies that contain relatively few queens because these are the colonies that benefit most from recruiting new queens (Brown and Keller 2000, 2002). This hypothesis has been proposed for highly polygynous ants, where queens frequently remain in their mother nest after mating and eventually disperse on foot with workers to initiate new colonies nearby (Bourke and Franks 1995; Keller 1995). This mode of reproduction may lead to intense local resource competition (Clark 1978) between queens within colonies and is often associated with dramatically male-biased sex ratios (reviewed in Bourke and Franks 1995; Crozier and Pamilo 1996). Moreover, in polygynous ants, queen life span is typically limited (Keller and Genoud 1997) and low queen number may cause egg and brood limitation in large colonies with abundant resources (Elmes and Keller 1993). Thus, as queen number decreases, local resource competition between related queens is reduced and below a certain threshold there might be a premium on recruiting new queens to enhance colony survival and productivity. This threshold and the value of new queens will depend on resource availability relative to the current number of queens.

Our study reveals that $P$. pallidula has an unusual breeding system. Colonies contain one or a few singly mated queens per colony. These queens are unrelated, thus leading to no variation in relatedness asymmetry across colonies. Yet sex ratios are highly split. Sex ratio specialization is correlated both with colony productivity and the breeding system (monogyny vs. polygyny) of the colonies. Monogynous colonies are relatively small and tend to produce male-biased sex ratios. By contrast, polygynous colonies are much larger and produce almost exclusively females. These data thus show that when colonies become more productive (and presumably larger) they shift from monogyny and male production to polygyny and female production, a pattern that has never been reported in social insects.

\section{Materials And Methods}

Thirty-five colonies of $P$. pallidula were sampled in a facultatively polygynous population located in Bruniquel (Tarn-
et-Garonne, France) just before the mating flight, on 29 June and 1 July 1999. This population was the same as the one previously studied by Aron et al. (1999) and Fournier et al. (2002). In this species, there is no overwintering brood (Passera 1980). Queens lay eggs from early March to early September. An early-laid fraction of these eggs gives rise to male and winged females that emerge at the end of June to early July, whereas a later fraction develops into workers (i.e., minors and soldiers) and emerge after the sexual brood (Bontpart 1964). Large samples of adult workers, males and winged females but no reproductive queens (see below), were collected and stored at $-20^{\circ} \mathrm{C}$ in $95 \%$ ethanol for subsequent sex ratio and genetic analyses.

\section{Colony Sex Ratios}

The colony sex ratios were obtained by sexing all the reproductives (pupae and alates) collected. Only colonies producing more than 20 sexuals were considered in this study; 26 of the 35 colonies collected were in accordance with this criterion. Overall, our sample consisted of 577 winged females and 1277 males. The numerical sex ratio was estimated as the proportion of winged females among sexuals in each colony (i.e., $N_{f} /\left[N_{f}+N_{m}\right]$ ). Colony sex-investment ratios, estimated as the proportional investment in winged females, were determined for each colony by adjusting the numbers of males and winged females by their respective dry weight at mating flight (males: $W_{m}=0.88 \pm 0.07 \mathrm{mg}$; females: $W_{f}$ $=6.14 \pm 1.44 \mathrm{mg}$; Keller et al. 1996). Investment ratios were corrected for sex-specific differences in energetic cost (due to differences in fat content and respiration rate; Boomsma et al. 1995) and were equal to $N_{f} C /\left(N_{f} C+N_{m}\right)$, where $C=\left(W_{f} / W_{m}\right)^{0.7}$.

\section{Breeding System and Relatedness Asymmetry}

Relatedness estimates were determined from genotype frequency data for workers $(n=260)$, winged females $(n=$ $165)$, and males $(n=194)$, obtained at four microsatellite loci: Ppal-03, Ppal-12, Ppal-83, and Ppal-19T (for details on genetic analyses see Fournier et al. 2002). In the study population, the number of alleles at these loci ranges from 10 to 16 and the expected heterozygosity ranges from 0.76 to 0.84 (Fournier et al. 2002). Regression relatedness among colony members $(r)$ was assessed for each colony, and averaged over colonies following the algorithm of Queller and Goodnight (1989; identity-by-descent method) by using the program Relatedness 5.0.8. Colonies were weighted equally and standard errors were obtained by jackknifing over colonies. We measured workers' relatedness asymmetry directly as the ratio of life-for-life relatedness of adult workers with male and female sexuals (pupae and alates; Boomsma and Grafen 1990; see also Brown and Keller 2000). Life-for-life relatednesses were obtained by multiplying regression relatednesses with males by 0.5 (Boomsma and Grafen 1991).

We tested for a possible correlation between the breeding system of the colonies (monogynous or polygynous with related or unrelated queens) and colony sex allocation. Because queens are extremely difficult to collect, the minimum number of queen(s) in each colony, their genotypes and the relatedness among nestmate queens in polygynous colonies 
were inferred from the observed genotypes of workers at all loci. This procedure is possible because the number of queens is relatively low in this species (Fournier et al. 2002). This method may lead to underestimating the number of queens because of the limited number of workers sampled (nonsampling error) and of the limited variation of genetic markers (nondetection error). Nonsampling error, that is, the probability of not sampling a worker from a mother who actually has maternity was relatively low because we sampled at least 10 workers per colony. Because a mother contributing a proportion $p$ of the offspring will be sampled with probability $1-(1-p)^{n}$, where $n$ is the sample size, the nonsampling probabilities were $<0.001$ for queens with $50 \%$ maternity and 0.028 for queens with $30 \%$ maternity (with $n=10$ ). In colonies where offspring of more than one queen were found in the first 10 workers we genotyped another five to 10 workers yielding even smaller nonsampling probabilities $(<0.005$ with $30 \%$ maternity when $n=15$ ). Nondetection error, that is, the probability of not detecting a supplementary queen due to different combinations of parental genotypes resulting in a same worker genotype was also low because $P$. pallidula queens mate only once with males to which they are unrelated (Fournier et al. 2002). The probability of the related queens producing indistinguishable offspring can be conservatively estimated as the probability that they mated with males carrying the same alleles at all loci. This probability is equal to the product of the sum of the squared allele frequencies (Pamilo 1993), 0.0014. Another potential problem is when drift by workers occurs between colonies, thus leading to an overestimate of the number of queens per colony. However, $P$. pallidula workers are extremely aggressive toward conspecific nonnestmates (Detrain and Pasteels 1992; pers. obs.). Moreover, colonies classified as polygynous always contained a significant number of workers from all matrilines, indicating that these workers were most likely produced by the queens of the colony rather than being workers accidentally coming from neighboring colonies.

We also inferred the pedigree relationships between pairs of queens with the software Kinship 1.3.1 (Goodnight and Queller 1999). This program reports likelihood ratios of a primary hypothesis versus a null hypothesis. For each colony, we tested the likelihood of a full-sister relationship between workers against the likelihood of a cousin relationship (i.e., the expected relationship if colonies are headed by sister queens), or the likelihood of no relationship (i.e., the expected relationship if nestmate queens are unrelated). When the test full-sisters versus unrelated was significant, the hypothesis full-sisters was also tested against the hypothesis cousins by their mothers. When the first test was not significant, the hypothesis cousins by their mothers was tested against the hypothesis unrelated. Some workers were not likely to belong to the reconstituted class, but could not be excluded from existing ones either. These workers were not assigned to any class. Finally, for polygynous colonies, we estimated the pedigree effective queen number as the harmonic mean of the number of queens across colonies (Ross 1993).

\section{Resource Level}

The resource abundance hypothesis (Nonacs 1986) predicts a positive correlation between total sexual productivity and proportional investment in females. Therefore, we performed a correlation analysis on these two variables to estimate the influence of resource abundance on sex allocation.

\section{Statistical Analyses}

Deviations of the variables from normality were tested using the Shapiro-Wilk test. When logarithmic or angular transformations did not suffice to normalize the data, we used nonparametric statistics. When a Levene's test did not give evidence for homoscedasticity, we used median test (Kasuya 2001). To test simultaneously for the effect of the breeding system (i.e., monogyny vs. polygyny) and colony productivity on sex ratio, we performed an analysis of covariance (ANCOVA).

\section{RESUlTS \\ Colony Sex Ratios}

As expected from previous studies (Keller et al. 1996; Aron et al. 1999), the distribution of the sex ratios per colony was significantly different from a normal distribution (ShapiroWilk, $W=0.751$, df $=26, P=0.010)$ and was not skewed to one side $\left(g_{1}=0.332 \pm 0.456, \mathrm{~ns}\right)$. The negative kurtosis value $\left(g_{2}=-1.842 \pm 0.887, P<0.05\right)$ confirmed a bimodal distribution of the colony sex ratio in the study population. Of 26 colonies, $22(84.6 \%)$ had more than $80 \%$ sexuals of one sex: 13 colonies $(50.0 \%)$ were male-specialist, nine $(34.6 \%)$ were female-specialist, and four $(15.4 \%)$ produced males and winged females in more equal numbers. Twelve colonies $(46.2 \%)$ raised single-sex brood. Overall, $41.0 \%$ of all males and $33.4 \%$ of all winged females were produced in colonies rearing only a single sex. Because all colonies produced worker larvae, the absence of female sexuals in colonies producing mostly or exclusively males is not simply due to the presence of queens having no more sperm in their spermatheca (storage organ of sperm). The populationwide numerical sex ratio (proportion of winged females among sexuals) was 0.31 . Sex-investment ratio in females was 0.64 , giving a 1.8:1 female:male investment ratio.

\section{Breeding System}

From the 26 colonies sampled, genetic analyses revealed that 16 were monogynous and 10 were polygynous (six colonies with two matrilines, two with three matrilines, and two with four matrilines). Within the polygynous colony class, the pedigree effective queen number per colony was 2.40. The average relatedness between queens was $r_{q}=0.04 \pm$ 0.07 , a value not significantly different from zero (two-tailed $t$-test, $\left.t_{9}=0.579, n=10, P=0.577\right)$. That nestmate queens are generally unrelated was confirmed by tests of pedigree relationships between pairs of queens. These tests showed that in all but one colony most workers were classified as full-sisters $(45.8 \%)$ or unrelated $(48.3 \%)$. The single exception was a two-queen colony consisting of full-sisters $(77.8 \%)$ and cousins $(22.2 \%)$ workers. This colony was most likely headed by two sister queens.

There was a strong difference in sex allocation between monogynous and polygynous colonies (see Fig. 1), with monogynous colonies producing mostly male-biased broods and 
polygynous colonies producing only female-biased broods. Indeed, 12 of the 13 male-specialist colonies were monogynous, and all nine female-specialist colonies were polygynous (Fisher's exact test of independence, $P<0.0001$ ). The four colonies producing both sexes were monogynous. There was no significant association between sex ratio and queen number in polygynous colonies (Spearman rank correlation, $\left.r_{s}=0.252, n=10, P=0.451\right)$.

\section{Resource Level}

Total per colony sexual productivity in polygynous colonies (mean $\pm \mathrm{SD}=349.8 \pm 184.3 \mathrm{mg}, n=10$ ) was significantly higher than that observed in monogynous colonies $(73.0 \pm 46.9 \mathrm{mg}, n=16$; Median test, median $=120.25, P$ $=0.0001)$. In monogynous colonies, the proportional investment in females increased with total sexual productivity (Spearman rank correlation, $r_{s}=0.803, n=16, P=0.0019$ ). This correlation was not observed in polygynous colonies, in which proportional investment in females ranged between 0.97 and 1.00 for nine of 10 colonies.

\section{Relatedness asymmetry}

Nestmate workers were significantly more closely related in male-specialist colonies $(r=0.77 \pm 0.03)$ than in femalespecialist colonies $\left(0.48 \pm 0.08\right.$; two-tailed $t$-test, $t_{20}=3.570$, $n=22, P=0.002)$. In male-specialist colonies, the regression relatedness values $( \pm$ SE) between workers and sexuals were $r_{w-f}=0.57 \pm 0.06(n=4)$ and $r_{w-m}=0.49 \pm 0.06(n$ $=13$ ). In female-specialist colonies, they were $r_{w-f}=0.32$ $\pm 0.11(n=9)$ and $r_{w-m}=0.17 \pm 0.16(n=5)$. To test whether the male-specialist and female-specialist colonies had different relatedness asymmetry, we first used a repeatedmeasures ANOVA. A difference between $r_{w-f}$ and $r_{w-m}$ between the two types of colonies would be reflected by a significant interaction term. This analysis showed that workers' relatedness asymmetry was lower, but not significantly so in male-specialist $(R A=2.34: 1)$ than female-specialist (3.75:1) colonies (repeated-measures ANOVA, $F_{1,7}=0.33$, $P=0.583$ ). The same conclusion was used by comparing the relatedness asymmetry between the two types of colonies with a nonparametric test (Mann-Whitney $U$-test, $z=-1.47$, $P=0.142)$.

Similarly, there was no significant difference in relatedness asymmetry between monogynous colonies $(R A=2.66: 1)$ and polygynous ones $\left(3.32: 1\right.$; repeated-measures ANOVA, $F_{1,11}$ $=1.75, P=0.213$; Mann-Whitney $U$-test, $z=-1.57, P=$ $0.116)$. Within polygynous colonies there was no significant association between sex ratio and queen number (Spearman rank correlation, $\left.r_{s}=0.252, n=10, P=0.451\right)$, nor between sex ratio and relatedness among nestmate queens (Spearman rank correlation, $\left.r_{s}=0.46, n=10, P=0.167\right)$.

Altogether, these data indicate that sex-ratio specialization did not result from between-colony variations in relatedness asymmetries. Rather, they show that the relative investment in females was correlated both with the breeding system (monogyny vs. polygyny) and sexual productivity. This was confirmed by an ANCOVA analysis that showed both a significant effect of breeding system $\left(F_{1,22}=60.13, P<0.0001\right)$ and sexual productivity $\left(F_{1,22}=24.99, P=0.0001\right)$. The

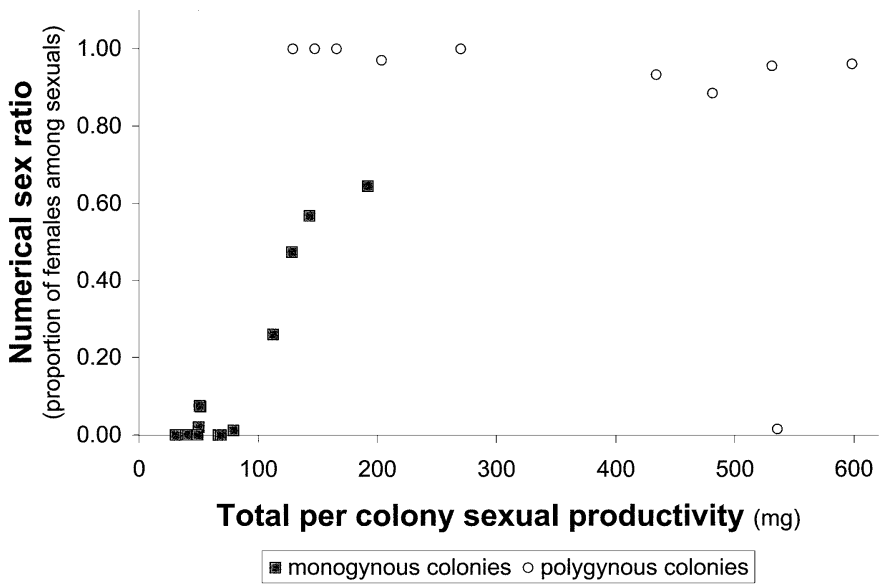

FIG. 1. Proportion of winged females among sexuals as a function of the total sexual productivity for monogynous and polygynous Pheidole pallidula colonies.

interaction between breeding system and sexual productivity was also significant $\left(F_{1,22}=36.10, P<0.0001\right)$, reflecting the fact that an increase in sexual productivity was associated with an increase in female bias only in monogynous colonies.

\section{DISCUSSION}

The first surprising result of this study is that the average relatedness between nestmate queens is not significantly greater than zero. The pedigree analyses indeed showed that in all but one colony workers were either full-sisters or unrelated, the expected pattern if colonies are headed by one queen or several unrelated queens. The only exception was a colony that contained cousins. The most likely breeding structure of this colony was that it was headed by two sister queens. The finding that most polygynous colonies contained unrelated queens contrast with the breeding structure of most ant species, in which nestmate queens are generally related (Keller 1995) as a result of queens being predominantly recruited from within the nest. Very low relatedness between queens has been reported only in a few ant species, and these are all highly polygynous species. In most of these species queens are also recruited from within the nest, but the high number of queens per colony results in a low relatedness both between nestmate queens and workers (Keller 1995). Hence, the finding that $P$. pallidula queens are unrelated is surprising given that the effective number of queens per colony was low and the relatedness between nestmate workers high.

The presence of several unrelated queens could possibly be accounted for if new colonies were initiated by several unrelated queens. This mode of colony founding (primary polygyny) occurs in a significant proportion of ant species, but in almost all cases it is unstable because all but one queen are killed-either as a result of fights between queens and/ or queen execution by workers-when the first workers eclose from the pupae (Bernasconi and Strassmann 1999; Holldobler and Wilson 1990). Moreover, contrary to what is predicted under primary polygyny, our study and a previous report (Bontpart 1964) suggest that queen number increases when colonies become larger. Indeed, we found that polygynous colonies produced a nearly five times more biomass 
of sexuals than monogynous individuals. This accords with the finding that $P$. pallidula polygynous colonies are markedly larger than monogynous colonies (15,000 and 5000 workers, respectively; Bontpart 1964). Hence, these data suggest that small colonies are monogynous and that they become polygynous as they grow older and larger.

A shift from monogyny to polygyny associated with a change in colony size could be due to unrelated queens being recruited when colonies become older, larger, and more productive. However, it is unclear why colonies would benefit from recruiting additional unrelated queens once they have reached a given size. Alternatively, the association between colony size and queen number may stem from colony fusion. Colony fusion has been reported in a few ants, but these are species where nestmate queens are related and where new colonies are produced by budding (a process where queens leave the nest on foot with workers to initiate a new colony nearby; Herbers 1993). Thus, if colony fusion occurs in $P$. pallidula, the pattern would be quite different from what has been described in other species because it would involve fusion between colonies in which individuals are completely unrelated. Another possible explanation is that polygyny could arise from intraspecific parasitism (Bourke and Heinze 1994). This hypothesis seems unlikely, however, because it does not account for the occurrence of polygyny in large colonies only.

The second surprising finding of this study is that polygynous colonies produced almost exclusively female sexuals, whereas monogynous colonies produced either only males or both male and female sexuals. An association between queen number and sex allocation has been reported in several ant species, but in most other species polygynous colonies tend to specialize on male production (e.g., Myrmica sulcinodis, Elmes 1987; Leptothorax longispinosus, Herbers 1990; Leptothorax acervorum, Chan and Bourke 1994; Chan et al. 1999; Myrmica tahoensis, Evans 1995; Formica podzolica, Deslippe and Savolainen 1995; Solenopsis invicta, Vargo 1996). The production of males in polygynous colonies has generally been explained by the relatedness asymmetry being lower in these colonies than in monogynous ones (but see Brown and Keller 2000). Interestingly, variation in queen number should not lead to variation in relatedness asymmetry in $P$. pallidula because queens are unrelated. Indeed, we found no significant difference in relatedness asymmetry between monogynous and polygynous colonies. In the two types of colonies the relatedness asymmetry was not significantly different from $3: 1$, the expected value when colonies are headed by one or several unrelated queens, queens are singly mated, and workers do not reproduce (Hamilton 1964a,b; Trivers and Hare 1976; Boomsma 1993).

Our data thus demonstrate that patterns of sex allocation are not associated with differences in relatedness asymmetry in $P$. pallidula. This is consistent with a previous study showing that the mean relatedness among workers was significantly higher in male-specialist than female-specialist colonies (Aron et al. 1999). Interestingly, a similar sex-specific specialization associated with variation in queen number may also occur in another ant of the same genus, Pheidole desertorum (Helms 1999). In this species, male-specialist colonies were headed by one singly mated queen, whereas some fe- male-specialist colonies had genotype compositions that were not consistent with monogyny and single mating. The low resolution of the allozyme markers used in this study did not allow us to determine accurately whether these colonies were headed by a single multiply mated queen or by several queens. Nor was it possible to determine precisely the proportion of female-producing colonies that were not simple families with one singly mated queen.

Our data are also not in line with the predictions and assumptions of the queen replenishment hypothesis, one of the two other leading hypotheses proposed to account for split sex ratios in ants. This hypothesis is based on the assumption that queens are mostly or only recruited within their parental colony because colonies produce queens when they benefit from the recruitment of new queens. This clearly was not the case because queens were unrelated. Thus, the queen replenishment hypothesis cannot apply to $P$. pallidula.

Our data were only partly in line with predictions and assumptions of the third hypothesis, the resource level hypothesis. This hypothesis has been proposed to account for the greater relative investment in females by more productive colonies. The idea is that large colonies that have more resources would still raise male brood but direct a greater proportion of female larvae to the queen developmental pathway (Nonacs 1986). The association between colony productivity and investment ratios may also stem from a shortage of brood, for example, if large colonies headed by a single queen are egg limited (Rosenheim et al. 1996). As a result, workers would benefit by producing the more expensive sex, typically females, in larger colonies. Our data show that larger colonies indeed had a relatively higher investment in females than smaller colonies. However, most large colonies produced no males, contrary to what is predicted under the resource level hypothesis. Moreover, the size of $P$. pallidula colonies is not very large, raising doubts that a shortage of brood due to constraints on queen fecundity may really occur. In addition, larger colonies were also polygynous, suggesting that a shortage of brood in these colonies is quite unlikely.

The finding that female sexuals are mainly produced by polygynous colonies suggests a new hypothesis for the occurrence of split sex ratio in $P$. pallidula and other species characterized by the presence of both monogynous and polygynous colonies in the same populations. This new hypothesis, proposed by David Queller (pers. com.), builds on the concept of the tragedy of the commons. Theoretical work showed that queens may possibly gain partial control over colony sex ratio in monogynous colonies by limiting the number of female eggs, hence forcing workers to raise males (Reuter and Keller 2001). A study in a monogynous population of the fire ant Solenopsis invicta indeed showed that about half the queens force workers to raise males by laying a high proportion of male eggs and presumably limiting the number of female eggs (Passera et al. 2001). Interestingly, with multiple queens, especially multiple unrelated queens, one expects a competition over who lays the eggs (D. C. Queller, pers. com.). Each queen would prefer to be the mother of as much of the offspring as possible. The ensuing overabundance of eggs may allow workers to manipulate sex ratio to their own advantage. Given the high relatedness asymmetry, workers should favor a female bias in their colony, 
which would tend to also lead to a female-biased sex ratio investment at the population level. As a result, queens in monogynous colonies would benefit to produce mainly or only males, hence leading to split sex ratio in the population. The overall investment at the population level may range from $1: 1$ to $3: 1$ depending on the proportion of monogynous and polygynous colonies and the cost of sex-ratio manipulation.

Several factors are expected to influence whether queens can effectively limit the number of female eggs in monogynous colonies (Reuter and Keller 2001). In that respect an important aspect of $P$. pallidula biology is the fact that sexuals (males and females) and workers develop from eggs laid at different periods of the year. Eggs laid in early spring develop into sexuals, whereas eggs laid later in the season develop into workers. This temporal partitioning of worker and sexual production should give queens great power over colony sex ratio because limitation in female eggs in early spring is not associated with decreased investment in workers. Thus, colony sex ratio in monogynous colonies is expected to mostly depend on how precisely queens can adjust the number of eggs compared to the colony need. Because there is always some uncertainty about the amount of resources available, queens cannot exactly adjust the number of eggs to colony needs, thus allowing workers to also influence sex ratio, workers' power being greater in colonies with a greater egg surplus. Temporal and spatial variation in resource availability should translate into intercolony variation in egg surplus and consequently variation in colony sex ratio. Indeed, there was significant variation in sex ratio between monogynous colonies. By contrast, the overabundance of eggs resulting from the tragedy of the commons in polygynous colonies should give greater power to workers and thus little variation in colony sex ratios, as was the case (all but one colony produced almost exclusively female sexuals).

There are several ways to test the tragedy of the commons sex ratio hypothesis. For example, experimental increase in the number of eggs in monogynous colonies and experimental decrease in the number of eggs in polygynous colonies should lead to a shift in sex ratio in both types of colonies. Of interest would also be to investigate why there is no difference in the primary sex ratio (at the egg stage) between male- and female-specialist, thus presumably monogynous and polygynous, colonies (Keller et al. 1996). Queens in monogynous colonies do perhaps still produce diploid eggs because monogynous colonies are the "balancing class" (Boomsma and Grafen 1991) in the population. Inversely, the production of male eggs in polygynous colonies may be retained because under some conditions these males are not eliminated. Clearly, more studies on the relationships between egg limitation, primary sex ratio, and secondary sex ratio are required to understand whether and to what extent a tragedy of the commons in polygynous colonies translates into a shift from queen control to worker control over sex ratio.

In conclusion, this study uncovered a new type of colony organization in ants characterized by facultative polygyny, low effective queen number, single mating by queens, zero relatedness between nestmate queens, and polygyny occurring only in more productive (and presumably larger) colonies. Additional studies are needed to unravel the mecha- nisms responsible for the shift from monogyny to polygyny and determine why it occurs only in larger colonies. The other interesting finding of this study is that there is a strong split sex ratio in $P$. pallidula and it is not associated with differences in relatedness asymmetry. The reasons why the polygynous and more productive colonies produced only females are unclear and also warrant further studies.

\section{ACKNOWLEDGMENTS}

We thank J. J. Boomsma, W. D. Brown, M. Chapuisat, C. Devigne, J. M. Herbers, D. C. Queller, an anonymous reviewer and the associate editor for comments on the manuscript. This work was supported by grants from the Belgian Fonds National de la Recherche Scientifique, the Fonds Defay, the Banque Nationale de Belgique, the University of Brussels (SA), the Tournesol exchange program (SA and LP), the Fondation de Meurs-François (DF), the Fondation Van Buuren (DF), and several grants from the Swiss National Science Foundation (LK).

\section{Literature Cited}

Aron, S., E. Campan, J. J. Boomsma, and L. Passera. 1999. Social structure and split sex ratios in the ant Pheidole pallidula. Ethol. Ecol. Evol. 11:209-227.

Bernasconi, G., and J. E. Strassmann. 1999. Cooperation among unrelated individuals: the ant foundress case. Trends Ecol. Evol. 14:477-482.

Bontpart, H. 1964. Recherches préliminaires sur la biologie de Pheidole pallidula Nyl. (Hyménoptère Formicoidea Myrmicidae). Université de Toulouse-Faculté des Sciences, Toulouse.

Boomsma, J. J. 1993. Sex ratio variation in polygynous ants. Pp. 86-109 in L. Keller, ed. Queen number and sociality in insects. Oxford Univ. Press, Oxford, U.K.

Boomsma, J. J., and A. Grafen. 1990. Intraspecific variation in ant sex-ratios and the Trivers-Hare hypothesis. Evolution 44: 1026-1034.

- 1991. Colony-level sex ratio selection in the eusocial Hymenoptera. J. Evol. Biol. 3:383-407.

Boomsma, J. J., L. Keller, and M. G. Nielsen. 1995. A comparative analysis of sex ratio investment parameters in ants. Funct. Ecol. 9:743-753.

Bourke, A. F. G., and G. L. Chan. 1994. Split sex ratios in ants with multiple mating. Trends Ecol. Evol. 9:120-122.

Bourke, A. F. G., and N. R. Franks. 1995. Social evolution in ants. Princeton Univ. Press, Princeton, NJ.

Bourke, A. F. G., and J. Heinze. 1994. The ecology of communal breeding: the case of multiple-queen leptothoracine ants. Philos. Trans. R. Soc. Lond. B 345:359-372.

Brown, W. D., and L. Keller. 2000. Colony sex ratios vary with queen number but not relatedness asymmetry in the ant Formica exsecta. Proc. R. Soc. Lond. B 267:1751-1757.

- 2002. Queen recruitment and split sex ratios in polygynous colonies of the ant Formica exsecta. Ecol. Lett. 5:102-109.

Chan, G. L., and A. F. G. Bourke. 1994. Split sex ratios in a multiple-queen ant population. Proc. R. Soc. Lond. B 258:261-266.

Chan, G. L., A. Hingle, and A. F. G. Bourke. 1999. Sex allocation in a facultatively polygynous ant: between-population and between-colony variation. Behav. Ecol. 10:409-421.

Chapuisat, M., and L. Keller. 1999. Testing kin selection with sex allocation data in eusocial Hymenoptera. Heredity 82:473-478.

Charnov, E. L. 1978. Sex-ratio selection in eusocial Hymenoptera. Am. Nat. 112:317-326.

Clark, A. B. 1978. Sex ratio and local resource competition in a prosimian primate. Science 201:163-165.

Crozier, R. H., and P. Pamilo. 1992. Sex allocation in social insects: problems in prediction and estimation. Pp. 369-383 in D. L. 
Wrensch and M. A. Ebbert, eds. Evolution and diversity of sex ratio in insects and mites. Chapman and Hall, New York.

1996. Evolution of social insect colonies: sex allocation and kin selection. Oxford Univ. Press, Oxford, U.K.

Deslippe, R. J., and R. Savolainen. 1995. Sex investment in a social insect: the proximate role of food. Ecology 76:375-382.

Detrain, C., and J. M. Pasteels. 1992. Caste polyethism and collective defense in the ant, Pheidole pallidula: the outcome of quantitative differences in recruitment. Behav. Ecol. Sociobiol. 29:405-412.

Elmes, G. W. 1987. Temporal variation in colony populations of the ant Myrmica sulcinodis. II. Sexual production and sex ratios. J. Anim. Ecol. 56:573-583.

Elmes, G. W., and L. Keller. 1993. Distribution and ecology of queen number in ants of the genus Myrmica. Pp. 294-307 in L. Keller, ed. Queen number and sociality in insects. Oxford Univ. Press, Oxford, U.K.

Evans, J. D. 1995. Relatedness threshold for the production of female sexuals in colonies of a polygynous ant, Myrmica tahoensis, as revealed by microsatellite DNA analysis. Proc. Natl. Acad. Sci. USA 92:6514-6517.

Fournier, D., S. Aron, and M. C. Milinkovitch. 2002. Investigation of the population genetic structure and mating system in the ant Pheidole pallidula. Mol. Ecol. 11:1805-1814.

Goodnight, K. F., and D. C. Queller. 1999. Computer software for performing likelihood tests of pedigree relationship using genetic markers. Mol. Ecol. 8:1231-1234.

Hamilton, W. D. 1964a. The genetical evolution of social behavior. I. J. Theor. Biol. 7:1-16.

1964b. The genetical evolution of social behavior. II. J. Theor. Biol. 7:17-52.

Helms, K. R. 1999. Colony sex ratios, conflict between queens and workers, and apparent queen control in the ant Pheidole desertorum. Evolution 53:1470-1478.

Herbers, J. M. 1990. Reproductive investment and allocation ratios for the ant Leptothorax longispinosus: sorting out the variation. Am. Nat. 136:178-208.

. 1993. Ecological determinants of queen number in ants. Pp. 262-293 in L. Keller, ed. Queen number and sociality in insects. Oxford Univ. Press, Oxford, U.K.

Herbers, J. M., C. J. DeHeer, and S. Foitzik. 2001. Conflict over sex allocation drives conflict over reproductive allocation in perennial social insect colonies. Am. Nat. 158:178-192.

Hölldobler, B., and E. O. Wilson. 1990. The ants. Springer-Verlag, Berlin.

Kasuya, E. 2001. Mann-Whitney $U$ test when variances are unequal. Anim. Behav. 61:1247-1249.

Keller, L. 1995. Social life: the paradox of multiple-queen colonies. Trends Ecol. Evol. 10:355-360.
Keller, L., and M. Chapuisat. 1999. Cooperation among selfish individuals in insect societies. BioScience 49:899-909.

Keller, L., and M. Genoud. 1997. Extraordinary lifespans in ants: a test of evolutionary theories of ageing. Nature 389:958-960.

Keller, L., and H. K. Reeve. 1999. Dynamics of conflicts within insect societies. Pp. 153-175 in L. Keller, ed. Levels of selection in evolution. Princeton Univ. Press, Princeton, NJ.

Keller, L., S. Aron, and L. Passera. 1996. Internest sex-ratio variation and male brood survival in the ant Pheidole pallidula. Behav. Ecol. 7:292-298.

Nonacs, P. 1986. Ant reproductive strategies and sex allocation theory. Q. Rev. Biol. 61:1-21.

Pamilo, P. 1991a. Evolution of colony characteristics in social insects. I. Sex allocation. Am. Nat. 137:83-107.

. 1991b. Evolution of colony characteristics in social insects. II. Number of reproductive individuals. Am. Nat. 138:412-433. 1993. Polyandry and allele frequency differences between the sexes in the ant Formica aquilonia. Heredity 70:472-480.

Passera, L. 1978. Une nouvelle catégorie d'oeufs alimentaires: les oeufs alimentaires émis par les reines vierges de Pheidole pallidula (Nyl.) (Formicidae, Myrmicinae). Insect. Soc. 25: 117-126.

1980. La ponte d'oeufs préorientés chez la fourmi Pheidole pallidula (Nyl.) (Hymenoptera-Formicidae). Insect. Soc. 27: 79-95.

Passera, L., S. Aron, E. L. Vargo, and L. Keller. 2001. Queen control of sex ratio in fire ants. Science 293:1308-1310.

Queller, D. C., and K. F. Goodnight. 1989. Estimating relatedness using genetic markers. Evolution 43:258-275.

Queller, D. C., and J. E. Strassmann. 1998. Kin selection and social insects. BioScience 48:165-175.

Ratnieks, F. L. W. 1991. Facultative sex allocation biasing by workers in social Hymenoptera. Evolution 45:281-292.

Ratnieks, F. L. W., and J. J. Boomsma. 1997. On the robustness of split sex ratio predictions in social Hymenoptera. J. Theor. Biol. 185:423-439.

Reuter, M., and L. Keller. 2001. Sex ratio conflict and worker production in eusocial Hymenoptera. Am. Nat. 158:166-177.

Rosenheim, J. A., P. Nonacs, and M. Mangel. 1996. Sex ratios and multifaceted parental investment. Am. Nat. 148:501-535.

Ross, K. G. 1993. The breeding system of the fire ant Solenopsis invicta: effects on colony genetic structure. Am. Nat. 141: $554-576$.

- 2001. Molecular ecology of social behaviour: analyses of breeding systems and genetic structure. Mol. Ecol. 10:265-284.

Trivers, R. L., and H. Hare. 1976. Haplodiploidy and the evolution of the social insects. Science 191:249-263.

Vargo, E. L. 1996. Sex investment ratios in monogyne and polygyne populations of the fire ant Solenopsis invicta. J. Evol. Biol. 9: 783-802.

Corresponding Editor: M. Morgan 